\title{
Transposition of the Great Arteries and Coarctation of the Aorta in an Infant Presenting with Bronchiolitis An incidental finding
}

*Khaloud S. Al-Mukhaini ${ }^{1}$ and Ala M. Mohamed ${ }^{2}$

$$
\begin{aligned}
& \text { تعاكس الشرايين الكبرى وتضيق الشريان الأبكر في رضيع مصاب } \\
& \text { بالتهاب القصيبات الموائية } \\
& \text { إكتشاف عرضي }
\end{aligned}
$$

خلود سعيد المخينية وعلاء مصطفى محمد

ABSTRACT: The transposition of the great arteries (TGA) is a complex congenital heart disease which usually presents as cyanosis in neonates with limited mixing between the systemic and pulmonary circulatory systems. A delayed diagnosis of TGA can lead to ventricular failure. We report a six-week-old infant who was admitted to the paediatric Intensive Care Unit of the Royal Hospital, Muscat, Oman, in 2016 for bronchiolitis. During admission, she was incidentally diagnosed with TGA and coarctation of the aorta. Postnatal screening, including the use of pulse oximetry, plays a significant role in avoiding a late diagnosis of TGA; however, this screening tool is not widely used in Oman. Moreover, the common practice of applying a pulse oximetry probe only to the foot may have been limited in the current case due to the reverse differential saturation between the upper and lower limbs caused by this particular combination of lesions.

Keywords: Transposition of Great Arteries; Cyanosis; Neonatal Screening; Pulse Oximetry; Case Report; Oman.

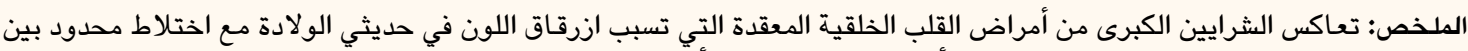

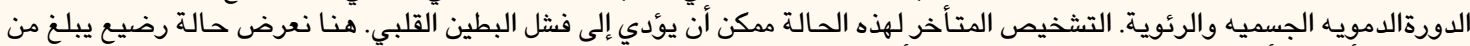

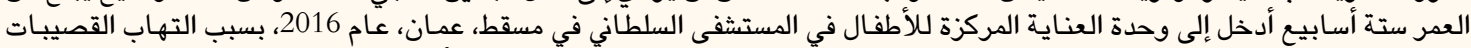

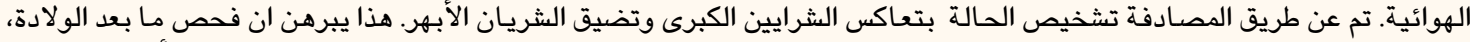

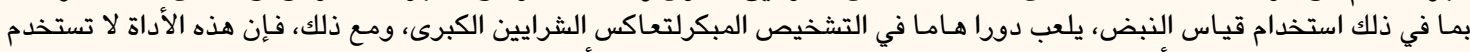

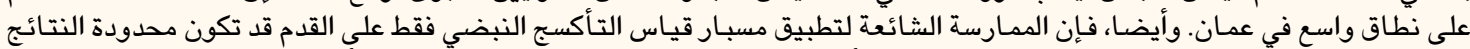

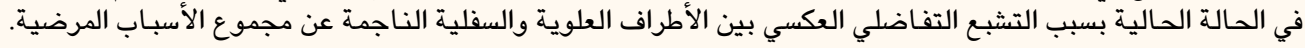

$$
\begin{aligned}
& \text { الكلمات المفتاحية؛ تعاكس الشرايين الكبرى؛ ازرقاق؛ فحص حديثي الولادة؛ التأكسج النبضي؛ تقرير حالة؛ عمان. }
\end{aligned}
$$

$\mathrm{M}$ ODERATE TO SEVERE CONGENITAL HEART diseases occur in approximately six in 1,000 live births. ${ }^{1}$ Of these, the transposition of the great arteries (TGA) is a major condition in which the aorta and pulmonary arteries do not arise from their respective ventricles, resulting in ventriculoarterial discordance and parallel pulmonary and systemic circulation. ${ }^{2}$ While most infants are diagnosed with TGA in the neonatal period, a subgroup of children are diagnosed at a much later stage. A delayed presentation of TGA carries additional complications-such as congestive heart failure in patients with increased pulmonary blood flow and systemic ventricular failure in those with an intact ventricular septum-leading to a need for ventricular support devices and longer stays in the intensive care unit (ICU)., ${ }^{2,3}$ As such, the early diagnosis of this major lesion can avoid associated morbidity and mortality. ${ }^{4}$

\section{Case Report}

A six-week-old infant girl was admitted to the paediatric ICU of the Royal Hospital, Muscat, Oman, in 2016 with symptoms of respiratory distress. The infant had been born at term with a birthweight of $2.38 \mathrm{~kg}$. The postnatal course was uneventful and she was discharged and sent home on the second day of life. There was no maternal history of diabetes and no history of cardiac diseases among the family members. At the age of one month, the infant had been evaluated 


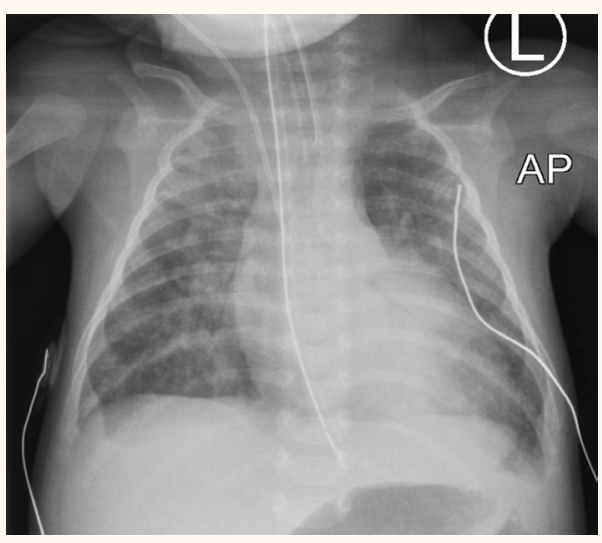

Figure 1: Anteroposterior chest X-ray of a six-week-old female infant showing plethoric lung fields.

for a febrile illness and respiratory distress and diagnosed with bronchiolitis. At admission, her weight and length was $3.00 \mathrm{~kg}$ and $52 \mathrm{~cm}$, respectively. Due to difficulties in breathing, noninvasive ventilation in the form of continuous positive airway pressure was initiated; however, as the breathing difficulties persisted, she was later intubated.

Following admission, the patient was noted to have a wide pulse pressure and a pansystolic murmur with peripheral pulses of adequate volume, including femoral pulses. In addition, she had features of congestive heart failure with cardiomegaly and congested lungs [Figure 1]. Given these clinical features, an echocardiogram was performed which showed discordant ventriculoarterial connections, good biventricular function, a large unrestrictive ventricular septal defect (VSD) measuring $8 \times 7 \mathrm{~mm}$, coarctation of the aorta and a large patent ductus arteriosus (PDA) of $6.7 \mathrm{~mm}$, supplying the distal aorta with a bidirectional shunt [Figure 2]. Notably, she had reversed differential saturation between the upper and lower limbs with oxygen saturation of $80 \%$ in the right hand and $100 \%$ in the lower limb. Her fraction of inspired oxygen level was 0.45 . A respiratory viral panel was positive for a rhinovirus infection.

On the ninth day following admission, a singlestage surgery was performed combining an arterial switch operation with an aortic arch repair and VSD closure. The bypass and cross-clamp time was 240 and 137 minutes, respectively. The postoperative period was complicated by low cardiac output, renal impairment requiring peritoneal dialysis and a left-sided diaphragm weakness necessitating diaphragmatic plication. Following a period of noninvasive ventilatory support, the patient was discharged one month after admission while breathing room air. At a two-month follow-up visit, she was healthy.

\section{Discussion}

In TGA cases, the clinical presentation is affected by the presence of atrial, ventricular or ductal connections and the degree of mixing between the two circulatory systems. ${ }^{2}$ Some infants without circulatory mixing present earlier in shock, often urgently requiring a prostaglandin infusion and an atrial septostomy as a palliative measure while awaiting corrective surgery. In contrast, infants with significant defects (including large VSDs, atrial septal defects and PDAs) may present later with features of congestive heart failure and mild cyanosis following a decrease in pulmonary vascular resistance. ${ }^{2}$ In the current case, the patient had adequate-volume peripheral pulses due to a large PDA, despite the concomitant presence of a coarctation of the aorta.

An interesting observation in the current patient was the reversed differential cyanosis. The term
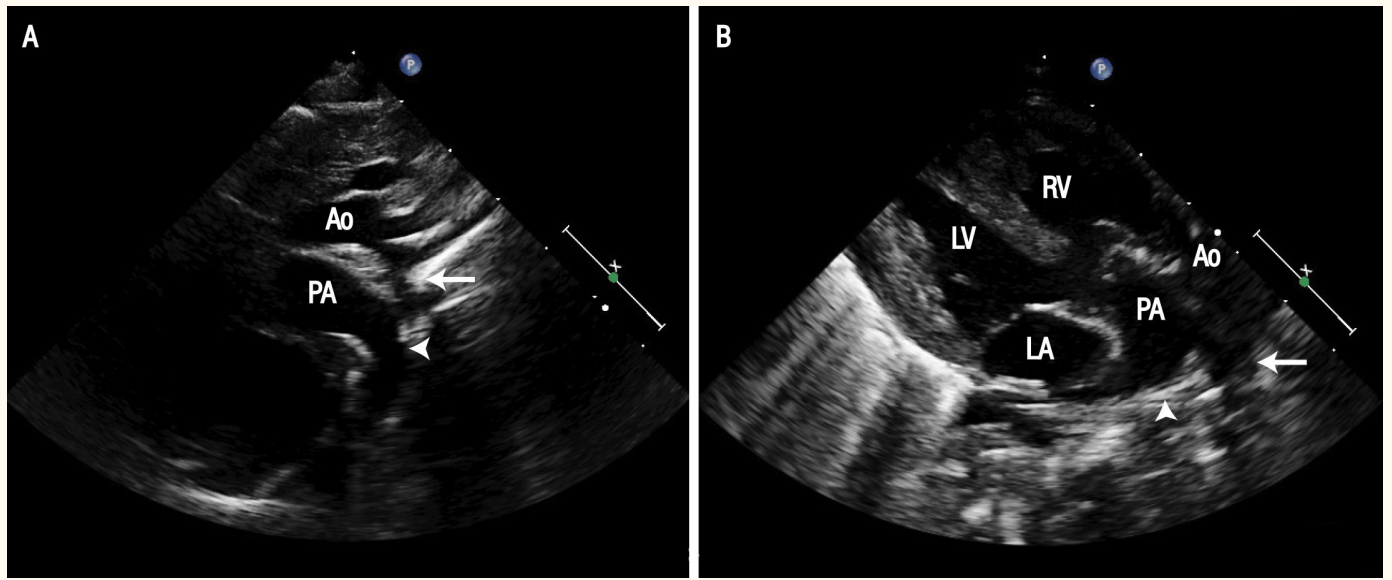

Figure 2: Echocardiograms of a six-week-old female infant in the (A) suprasternal and (B) parasternal long axis views showing coarctation (arrow) and the continuation of the arterial duct (arrowhead) into the descending aorta. Note the anterior aorta arising from the right ventricle and the posterior pulmonary artery.

Ao = ascending aorta; $P A=$ pulmonary artery; $L V=$ left ventricle; $R V=$ right ventricle; $L A=$ left atrium. 
differential cyanosis refers to the discrepancy between upper and lower limb saturation where the former is higher compared to the latter. ${ }^{5}$ This finding is often observed in children with a left-to-right shunt at the ductal level, either due to pulmonary hypertension or an obstruction in aortic blood flow anywhere proximal to the ductus. Reversed differential cyanosis, on the other hand, is seen in children with TGA in association with aortic arch abnormalities and pulmonary hypertension. ${ }^{2,5}$ In such cases, the deoxygenated blood from the right ventricle is pumped into the systemic circulatory system through the aorta to supply the head, neck and upper limbs while the oxygenated blood from the left ventricle is pumped into the pulmonary circulation via the pulmonary artery. ${ }^{2}$ The presence of a coarctation between the left subclavian artery and the ductus allows for the shunting of a portion of this blood-while the rest is ejected to the lungs-from the pulmonary artery to the descending aorta which supplies the rest of the torso and lower limbs. This leads to higher saturation in the lower limbs in comparison to the arms. ${ }^{2,5}$ While reversed differential cyanosis is pathognomonic in children with TGA, a PDA and elevated pulmonary vascular resistance or aortic arch abnormalities, it has also been reported in an infant presenting with a supracardiac total anomalous pulmonary venous connection. ${ }^{6}$

In recent years, fetal echocardiography has become an important tool for antenatal care. Patients with critical congenital heart lesions diagnosed antenatally have a better prognosis than those diagnosed postnatally, including a reduced risk of brain injury, as they can be rapidly transferred to a tertiary surgical centre and receive early intervention. ${ }^{4,7,8}$ Various international guidelines recommend antenatal anomaly screening, including the need for certain imaging views such as four chamber and ventricular outflow tract assessments. ${ }^{9}$ Staff training in obstetric ultrasonography techniques is therefore crucial to improve the antenatal detection of congenital heart diseases. In addition, neonatal screening for congenital cardiac anomalies should include pulse oximetry as a part of the clinical examination. This method of postnatal testing has been incorporated into numerous newborn screening programmes worldwide and is recommended by the American Academy of Pediatrics, American Heart Association and the American College of Cardiology. ${ }^{10,11}$

Overall, the percentage of severe congenital heart diseases diagnosed postnatally has increased from $58 \%$ with clinical examinations alone to $72 \%$ with pulse oximetry. ${ }^{10,12}$ Asymptomatic neonates should be screened after 24 hours of life or before discharge at two sites, including the right hand and foot. ${ }^{10}$
However, not all institutions incorporate screening at both the pre- and post-ductal sites; instead, some test only the post-ductal site in the foot, since most lesions have lower saturations in the foot due to a right-to-left shunt at the ductal level. ${ }^{10}$ This approach would miss a complex defect, as seen in the current patient who had higher saturation in the foot due to reversed differential saturation. Unfortunately, pulse oximetry screening is not mandatory in Omani health institutions and, when performed, may be restricted to the post-ductal site. As such, the researchers strongly recommend that these limitations be addressed in future screening practices in the country.

At birth, the left ventricle is of normal thickness in infants with TGA who have an intact ventricular septum; however, since it supports only low-pressure pulmonary circulation, the ventricle loses its muscle mass and becomes thin-walled by the time the child is 2-4 months old. ${ }^{13}$ In cases such as the current one, the systemic ventricle has a reduced risk of deconditioning due to the presence of a large VSD that exposes the ventricle to systemic or near-systemic pressure. ${ }^{2}$ Nevertheless, the presence of aortic arch abnormalities requires early surgery. ${ }^{2}$ An arterial switch operation is the surgical procedure of choice for TGA cases. ${ }^{14}$ However, a primary TGA repair can be still performed at 3-8 weeks of age, with similar results to those found for surgical repairs undertaken at an earlier age. ${ }^{3}$ In children with TGA and a large VSD, as in the present case, the surgery of choice is also an arterial switch operation. ${ }^{2}$ Edwin et al. reported that surgical correction in infants over two months old with TGA and an intact ventricular septum resulted in prolonged mechanical ventilation and increased hospital stays due to the deconditioning of the systemic ventricles. ${ }^{3}$

\section{Conclusion}

This case describes a patient with a significant congenital heart lesion diagnosed incidentally following her admission for bronchiolitis. As she had been asymptomatic at birth and no postnatal screening for cardiac anomalies was undertaken, the condition had gone undiagnosed. Neonatal and postnatal screening has been shown to play a major role in reducing undiagnosed cases of congenital heart diseases. The current case demonstrates that even a combination of two complex cardiac lesions can be missed both antenatally and postnatally. It is therefore recommended that universal postnatal pulse oximetry screening be implemented in healthcare institutions throughout Oman, with screening of both the pre- and post-ductal sites to include the right hand and one of the feet. 


\section{References}

1. Hoffman JI, Kaplan S. The incidence of congenital heart disease J Am Coll Cardiol 2002; 39:1890-900. doi: 10.1016/S07351097(02)01886-7.

2. Latham GI, Joffe DC, Eisses MI, Richards MI, Geiduschek JM. Anesthetic considerations and management of transposition of the great arteries. Semin Cardiothorac Vasc Anesth 2015; 19:233-42. doi: 10.1177/1089253215581852.

3. Edwin F, Mamorare H, Brink J, Kinsley R. Primary arterial switch operation for transposition of the great arteries with intact ventricular septum: Is it safe after three weeks of age? Interact Cardiovasc Thorac Surg 2010; 11:641-4. doi: 10.1510/ icvts.2010.243832

4. Eckersley L, Sadler L, Parry E, Finucane K, Gentles TL. Timing of diagnosis affects mortality in critical congenital heart disease. Arch Dis Child 2016; 101:516-20. doi: 10.1136/ archdischild-2014-307691.

5. Buckley MJ, Mason DT, Ross J Jr, Braunwald E. Reversed differential cyanosis with equal desaturation of the upper limbs: Syndrome of complete transposition of the great vessels with complete interruption of the aortic arch. Am J Cardiol 1965; 15:111-15. doi: 10.1016/0002-9149(65)90609-0.

6. Yap SH, Anania N, Alboliras ET, Lilien LD. Reversed differential cyanosis in the newborn: A clinical finding in the supracardiac total anomalous pulmonary venous connection. Pediatr Cardiol 2009; 30:359-62. doi: 10.1007/s00246-008-9314-0.
7. Hunter LE, Simpson JM. Prenatal screening for structural congenital heart disease. Nat Rev Cardiol 2014; 11:323-34. doi: $10.1038 /$ nrcardio.2014.34.

8. Peyvandi S, De Santiago V, Chakkarapani E, Chau V, Campbell A, Poskitt KJ, et al. Association of prenatal diagnosis of critical congenital heart disease with postnatal brain development and the risk of brain injury. JAMA Pediatr 2016; 170:e154450. doi: 10.1001/jamapediatrics.2015.4450.

9. Sharland G. Fetal cardiac screening: Why bother? Arch Dis Child Fetal Neonatal Ed 2010; 95:F64-8. doi: 10.1136/ adc. 2008.151225 .

10. Oster ME, Kochilas L. Screening for critical congenital heart disease. Clin Perinatol 2016; 43:73-80. doi: 10.1016/j. clp.2015.11.005

11. Kemper AR, Mahle WT, Martin GR, Cooley WC, Kumar P, Morrow WR, et al. Strategies for implementing screening for critical congenital heart disease. Pediatrics 2011; 128:e1259-67. doi: 10.1542/peds.2011-1317

12. Valmari P. Should pulse oximetry be used to screen for congenital heart disease? Arch Dis Child Fetal Neonatal Ed 2007; 92:F219-24. doi: 10.1136/adc.2005.090282.

13. Planche C, Lacour-Gayet F, Serraf A. Arterial switch. Pediatr Cardiol 1998; 19:297-307. doi: 10.1007/s002469900313.

14. Tchervenkov CI. Surgical management of transposition in the setting of obstruction within the aortic arch. Cardiol Young 2005; 15:106-10. doi: 10.1017/S1047951105001125. 